\title{
Photoluminescence characterization of Mg implanted GaN
}

\author{
C. Ronning, H. Hofsäss, A. Stötzler ${ }^{1}$, M. Deicher ${ }^{1}$, E.P. Carlson ${ }^{2}$, P.J. Hartlieb ${ }^{2}$, \\ T. Gehrke ${ }^{2}$, P. Rajagopal ${ }^{2}$, R.F. Davis ${ }^{2}$ \\ University Göttingen, II. Phys. Institute, Bunsenstr. 7-9, D-37073 Göttingen, Germany \\ ${ }^{1}$ University of Konstanz, Fakultät für Physik, Box M621, D-78457 Konstanz, Germany \\ ${ }^{2}$ North Carolina State University, Department of Materials Science and Engineering, Box \\ 7919, Raleigh, NC 27695, USA
}

\begin{abstract}
Single crystalline (0001) gallium nitride layers, capped with a thin epitaxial aluminum nitride layer, were implanted with magnesium and subsequently annealed in vacuum to 1150-1300 ${ }^{\circ} \mathrm{C}$ for $10-60$ minutes. Photoluminescence (PL) measurements showed the typical donor acceptor pair (DAP) transition at $3.25 \mathrm{eV}$ after annealing at high temperatures, which is related to optically active $\mathrm{Mg}$ acceptors in $\mathrm{GaN}$. After annealing at 1300 ${ }^{\circ} \mathrm{C}$ a high degree of optical activation of the implanted $\mathrm{Mg}$ atoms was reached in the case of low implantation doses. Electrical measurements, performed after removing the AlNcap and the deposition of $\mathrm{Pd} / \mathrm{Au}$ contacts, showed no p-type behavior of the GaN samples due to the compensation of the $\mathrm{Mg}$ acceptors with native $\mathrm{n}$-type defects.
\end{abstract}

\section{INTRODUCTION}

Magnesium is the commonly used impurity for p-type doping of gallium nitride ( $\mathrm{GaN}$ ) and it can be introduced into the lattice during chemical vapor deposition (CVD) of GaN layers in an easy way [1]. Sufficient p-type activation of the GaN:Mg-layers is reached after a subsequent annealing step at around $800{ }^{\circ} \mathrm{C}$. These p-type GaN-layers are successfully used for the fabrication of "blue" optoelectronic devices. However, the use of $\mathrm{GaN}$ is limited to such devices, because the growth process can result only into layered structures. The realization of lateral doped structures of $\mathrm{GaN}$ is therefore highly desirable in order to produce $\mathrm{GaN}$ based integrated microelectronics.

Lateral doping of semiconductors can be achieved by either in-diffusion or ion implantation of dopants through a structured mask. The diffusion method can be excluded in the case of GaN due to the fact that the diffusion of impurities in GaN starts at very high temperatures where the decomposition of the $\mathrm{GaN}$ surface/samples is already completed [2-3]. This early decomposition of the GaN surface at about $850^{\circ} \mathrm{C}$ also hampers the success of ion implantation doping of GaN [4]. The advantages of ion implantation (control of lateral and depth distributions, all elements are available) are compromised by the introduced radiation damage which has to be removed via annealing treatments. Annealing temperatures $\left(\mathrm{T}_{\mathrm{A}}\right)$ of about $1300{ }^{\circ} \mathrm{C}$ for more than 5 minutes are necessary for $\mathrm{GaN}$ to fulfil the rule of thumb claiming that implanted semiconductors should be annealed up to $2 / 3$ of the melting point for satisfying electrical activation $[1,5,6]$. Several special annealing procedures for temperatures above $900{ }^{\circ} \mathrm{C}$ have been investigated with limited success: rapid thermal annealing (RTA) [7,8], annealing under $\mathrm{N}_{2}$-overpressure [9], or the usage of $\mathrm{N}_{2}, \mathrm{NH}_{3}$ or atomic $\mathrm{N}$ fluxes, respectively [10,11]. Polycrystalline, sputter deposited AlN cap layers were also used to protect decomposition during annealing. 
However, depending on the crystalline quality of the sputtered AIN, good results were obtained only for some selected samples $[6,10]$.

In this article we present results on the basis of an improved annealing technique. Instead of polycrystalline AlN-cap layers, we used thin AlN layers epitaxially grown on top of GaN-samples to protect the GaN surface from decomposition during annealing after the ion implantation of $\mathrm{Mg}$. Magnesium was used because of its known behavior in $\mathrm{GaN}$ and the well known corresponding PL signatures.

\section{EXPERIMENTAL}

One-to-two $\mu \mathrm{m}$ thick epitaxial, monocrystalline and nominally undoped $\mathrm{GaN}$ films were grown on on-axis n-type, $\mathrm{Si}$-face $\alpha(6 \mathrm{H})-\mathrm{SiC}(0001)$ substrates at $1000{ }^{\circ} \mathrm{C}$ and 45 Torr using a vertical, cold-wall, RF inductively heated MOVPE deposition system [12]. High-temperature $\left(1100{ }^{\circ} \mathrm{C}\right)$ mono-crystalline AlN layers were deposited prior $(100 \mathrm{~nm})$ and following $(30 \mathrm{~nm})$ to the $\mathrm{GaN}$ growth. Deposition was performed using triethylaluminum (TEA) and triethylgallium (TEG) in combination with $1.5 \mathrm{SLM}$ of ammonia $\left(\mathrm{NH}_{3}\right)$ and 3 SLM of $\mathrm{H}_{2}$ diluent.

Magnesium was implanted with ion energies of $60 \mathrm{keV}$ or $120 \mathrm{keV}$ at room temperature. TRIM simulations gave a mean ion range of $70 \mathrm{~nm}(\mathrm{FWHM}=40 \mathrm{~nm})$ and 127 $\mathrm{nm}(\mathrm{FWHM}=101 \mathrm{~nm})$, respectively, for the two energies [13]. Thus, the implanted magnesium ions penetrated the AlN-cap layer in both cases, which was also experimentally checked and confirmed by SIMS measurements. The total implantation dose ranged between $10^{13} \mathrm{~cm}^{-2}$ and $10^{15} \mathrm{~cm}^{-2}$.

All implanted samples were annealed under vacuum $\left(<1 \cdot 10^{4}\right.$ mbar $)$ up to temperatures of $1300{ }^{\circ} \mathrm{C}$ for 10-30 minutes. The AlN cap layer inhibited surface decomposition of the $\mathrm{GaN}$ sample. Photoluminescence measurements (PL) were performed after each annealing step at low temperatures by exciting the $\mathrm{GaN}$ samples with a He-Cd laser $(3.81 \mathrm{eV})$. The AlN-cap layer was removed by dry etching in an ICP plasma ( $300 \mathrm{~W}$, bias: $10 \mathrm{~V}, 30 \mathrm{sec}$.) [14]. Hall measurements were done in Van-der-Pauw geometry after the deposition of $\operatorname{Pd}(50 \mathrm{~nm})-\mathrm{Au}(100 \mathrm{~nm})$ contacts at a rate of $0.1-0.2 \mathrm{~nm} / \mathrm{s}$ and $6 \cdot 10^{-6} \mathrm{mbar}$.

\section{RESULTS AND DISCUSSION}

The low temperature PL spectra of Mg-implanted GaN with a dose of $1 \cdot 10^{13} \mathrm{~cm}^{-2}$ are summarized in figure 1 as a function of annealing temperature and time. No PL lines were observed directly after ion implantation, which indicates a highly disturbed $\mathrm{GaN}$ lattice. This behavior was, of course, also observed for the higher implantation doses used in this study. The high defect density introduced into the crystal by the ion implantation process leads to non-radiative recombinations of the excited electrons with holes; thus, no luminescence is visible.

Intense PL lines have been detected after annealing the Mg implanted GaN sample at a temperature of $1200{ }^{\circ} \mathrm{C}$ for 11 minutes (see figure $1(\mathrm{~b})$ ). However, the intensity of the band edge luminescence is still about 2-3 orders of magnitude lower in comparison to asgrown, unimplanted GaN samples. This luminescence line at $3.467 \mathrm{eV}$ (commonly labeled as $\mathrm{I}_{2}$ ) originates from recombinations of excitons bound to shallow donors. The LO-phonon replica of this line at about $3.35 \mathrm{eV}$ could not be observed in the implanted sample an- 


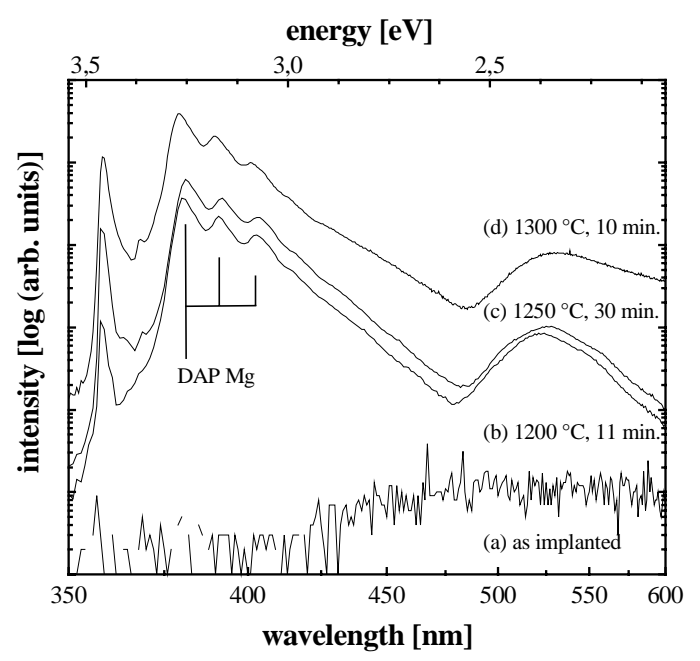

Figure 1. Photoluminescence spectra of GaN. The spectra were recorded in the situations: (a) as-implanted with $\mathrm{Mg}$, and (b-d) after annealing to several temperatures for different times. The implantation energy was $60 \mathrm{keV}$ and the implantation dose $1 \cdot 10^{13} \mathrm{~cm}^{-2}$.

nealed at $1200{ }^{\circ} \mathrm{C}$ for $11 \mathrm{~min}$ utes. However, it was observed as a shoulder after annealing at $1250{ }^{\circ} \mathrm{C}$ for 30 minutes and the PL intensity of the excitons also increased. A further increase of this $\mathrm{I}_{2}$-line took place after the $1300{ }^{\circ} \mathrm{C}$

annealing step for 10 minutes, as shown in Figure 1. This indicates that the implanted sample has been recovered to a large extent.

The luminescence peak, which appeared at $3.25 \mathrm{eV}$ after the high temperature annealing steps, is related to donor acceptor pair (DAP) transitions involving $\mathrm{Mg}$ acceptors. This line with its LO-phonon replicas is commonly seen in GaN samples doped during growth with $\mathrm{Mg}$ showing p-type activation [15]. Therefore, we can conclude that optical activation of the implanted $\mathrm{Mg}$ atoms was reached. After the $1300{ }^{\circ} \mathrm{C}$ annealing step a further increase of the intensity took place and the optical activation seems to be almost complete, because the intensity of the $3.25 \mathrm{eV}$ line with its phonon replicas is in the same order of PL-lines observed in GaN:Mg samples with an Mg concentration of about $10^{17-18}$ $\mathrm{cm}^{-3}$. This concentration corresponds well to the peak concentration of $\mathrm{Mg}$ atoms in the implanted region. Since we have never observed the PL-line at $3.25 \mathrm{eV}$ after implantation of $\mathrm{Be}, \mathrm{Li}, \mathrm{Si}, \mathrm{Ge}, \mathrm{In}$ and $\mathrm{Er}$ into $\mathrm{GaN}[11,16,17]$, these observations prove that the line at $3.25 \mathrm{eV}$ is only related to the implanted $\mathrm{Mg}$ acceptors, which is in agreement with Ref.

[18]. However, there is still a high intensity of the yellow PL-band observable between 2.0 and $2.6 \mathrm{eV}$ in figure $1 \mathrm{after}$ the $1300{ }^{\circ} \mathrm{C}$ annealing step, which indicates that remaining implantation defects are still present.

The low temperature PL-spectra of $\mathrm{Mg}$ implanted GaN samples annealed at $1250{ }^{\circ} \mathrm{C}$ for 30 minutes are shown in figure 2 as a function of the implantation dose. For comparison, the same scales of figure 1 were used in figure 2 . The spectrum of the implanted sample with $10^{13} \mathrm{~cm}^{-2} \mathrm{Mg}$ ions was already described above. With increasing implantation dose the $\mathrm{Mg}$ related DAP transition decreases, and finally the GaN samples implanted with a dose of $10^{15} \mathrm{~cm}^{-2}$ show no PL-transitions. One would not expect such a behavior, which was also observed after the $1300{ }^{\circ} \mathrm{C}$ annealing step, in completely recovered GaN:Mg samples. Therefore, an amount of residual defects, which strongly depends on the implantation dose, is still present in the annealed samples. This is supported by the fact that the behavior of the intensity of the yellow band is opposite to the behavior of the DAP transitions and therefore much higher in the GaN:Mg samples 


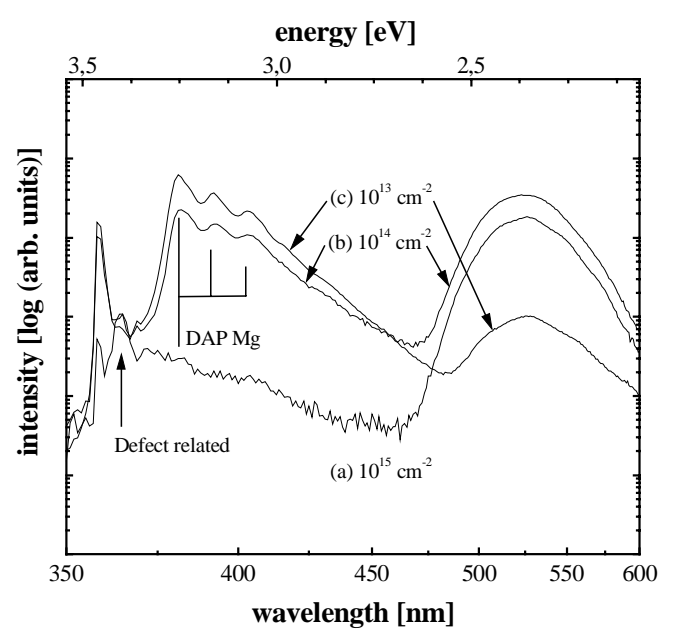

Figure 2. Photoluminescence spectra measured at low temperature of $\mathrm{GaN}$ as a function of the $\mathrm{Mg}$ implantation dose. (a) $10^{15} \mathrm{~cm}^{-2}$, (b) $10^{14} \mathrm{~cm}^{-2}$, and (c) $10^{13} \mathrm{~cm}^{-2}$. The annealing was performed at $1250{ }^{\circ} \mathrm{C}$ for 30 minutes under vacuum and the implantation energy was set to $60 \mathrm{keV}$.

implanted with the higher implantation dose (see figure 2). Furthermore, the intensity of the band edge PL of the $10^{15}$ $\mathrm{cm}^{-2} \mathrm{GaN}: \mathrm{Mg}$ is suppressed by two orders of magnitude and an additional PL-line appears at $3.40 \mathrm{eV}$. This line is most likely related to defects created during the implantation procedure, as this line was also observed with varying intensities after implantation of Be, $\mathrm{Li}, \mathrm{Si}, \mathrm{Ge}, \mathrm{In}$ and $\mathrm{Er}[11,17]$. We believe that this line is produced by nitrogen or gallium vacancies due to acceptor or donor bound excitons, because it appears also in unimplanted $\mathrm{GaN}$ samples depending on the growth conditions.

Finally, we want to compare PL-spectra obtained from GaN:Mg samples implanted with different ion energies. Figure 3 shows the PL spectra of two GaN samples annealed at $1250{ }^{\circ} \mathrm{C}$ for 30 minutes and implanted with a dose of $10^{13} \mathrm{~cm}^{-2}$ and an ion energy of 60 and $120 \mathrm{keV}$, respectively. The luminescence intensity of the $120 \mathrm{keV}$ implanted $\mathrm{GaN}$ is at almost all wavelengths about one order of magnitude higher. This is again opposite to the expected behavior, because the higher implantation energy yields to a larger spatial distribution of the implanted $\mathrm{Mg}$. The peak concentration is approximately a factor 2 lower compared to the $60 \mathrm{keV}$ implanted sample and the DAP transitions are more intense. This can be explained by the fact that the introduced damage is also distributed over a larger volume and less implantation defects remain after the annealing.

Electrical measurements were performed after removing the AlN-cap by dry etching in an ICP plasma (300 W, bias: $10 \mathrm{~V}, 30 \mathrm{sec}$.) [14] and the deposition of Pd/Au contacts. The contacts showed ohmic behavior over a range of $+/-5 \mathrm{~V}$, which is an important prerequisite for Hall effect measurements in Van-der-Pauw geometry [19,20]. First, we want to notice that an electrical signal was only measurable in the $\mathrm{Mg}$ implanted $\mathrm{GaN}$ samples, which were annealed above a temperature of $1250{ }^{\circ} \mathrm{C}$ for more than 30 minutes. For lower annealing temperatures the $\mathrm{GaN}$ samples were too resistive $\left(>10^{10} \Omega\right)$. The electrical measurements are summarized in table I.

In some cases the sign of the major charge carriers was not clear, because in several repeated measurements n- or p-type was measured. These measurements are indicated in the table I with $\mathrm{n} / \mathrm{p}$. This already indicates that the holes generated by the $\mathrm{Mg}$ acceptors are compensated by electrons. We assume that these donors are either due to remaining implantation defects or due to native donors from the as-grown $\mathrm{GaN}$-samples. For 


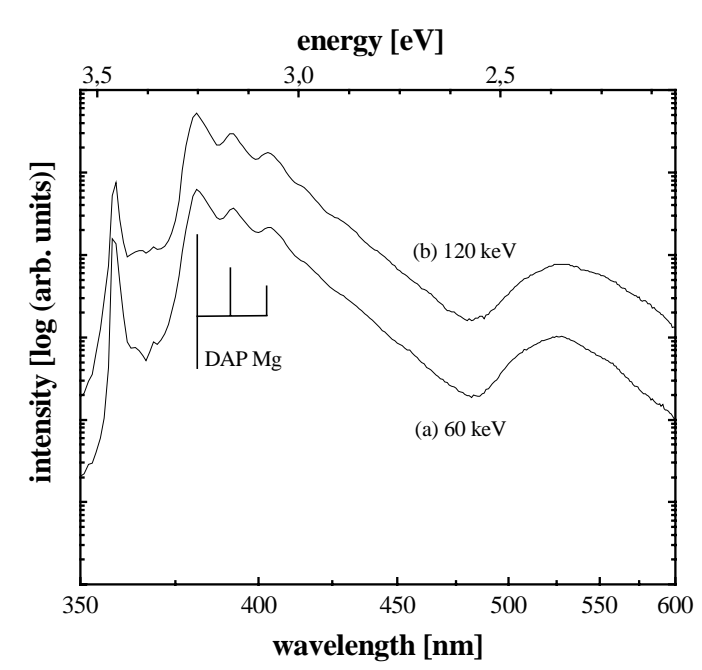

Figure 3. Photoluminescence spectra measured at low temperature of $\mathrm{GaN}$ as a function of implantation energy. (a) 60 $\mathrm{keV}$, and (b) $120 \mathrm{keV}$. The annealing was performed at $1250{ }^{\circ} \mathrm{C}$ for 30 minutes under vacuum and the implantation dose was $10^{13} \mathrm{~cm}^{-2}$.

comparison: the as-grown samples showed sheet concentrations of $1.5 \cdot 10^{13} \mathrm{~cm}^{-2}$, which is comparable with the introduced $\mathrm{Mg}$ acceptors for the low implantation doses used. Furthermore, we observed a decrease of the sheet resistance, sheet carrier con-

centration and mobility for the higher implanted doses, which is definitively due to the remaining implantation defects (see PL-results).

\section{CONCLUSIONS}

Single crystalline (0001) GaN layers, capped with a thin epitaxial aluminum nitride layer, were implanted with magnesium and subsequently annealed within the range of $1150-1300{ }^{\circ} \mathrm{C}$ for $10-60$ minutes in vacuum. PL measurements showed the typical DAP transition at $3.25 \mathrm{eV}$ after annealing at high temperatures, which is related to optically active $\mathrm{Mg}$ acceptors in GaN. For low doses, high ion energies and high annealing temperatures the PL spectra seems to be completely recovered; however, this is not the case, as shown for higher implantation doses, lower ion energies and lower annealing temperatures. Therefore, the electrical measurements showed no p-type behavior of the $\mathrm{GaN}$ samples due to the compensation of the $\mathrm{Mg}$ acceptors with native or implantation n-type defects. In order to reach electrical activation higher annealing temperatures and annealing times should be necessary. For such experiments better vacuum conditions during the annealing must be realized, because beyond $1300{ }^{\circ} \mathrm{C}$ the AlN-cap starts to oxidize in the presence of even low partial pressures of oxygen.

Table I. Results of Hall measurements on Mg-implanted GaN samples.

\begin{tabular}{|c|c|c|c|c|c|c|}
\hline \multicolumn{2}{|c|}{ Implantation } & \multicolumn{2}{|c|}{ Annealing } & \multicolumn{3}{c|}{ Electrical measurements } \\
\hline $\begin{array}{c}\mathrm{E}_{\text {Ion }} \\
{[\mathrm{keV}]}\end{array}$ & $\begin{array}{c}\text { Dose } \\
{\left[\mathrm{cm}^{-2}\right]}\end{array}$ & $\begin{array}{c}\mathrm{T}_{\mathrm{A}} \\
{\left[{ }^{\circ} \mathrm{C}\right]}\end{array}$ & $\begin{array}{c}\mathrm{t} \\
{[\mathrm{min} .]}\end{array}$ & $\begin{array}{c}\text { Sheet resi- } \\
\text { stance }[\mathrm{k} \Omega]\end{array}$ & $\begin{array}{c}\text { Sheet concen- } \\
\text { tration }\left[\mathrm{cm}^{-2}\right]\end{array}$ & $\begin{array}{c}\text { Mobility } \\
{\left[\mathrm{cm}^{2} / \mathrm{Vs}\right]}\end{array}$ \\
\hline 60 & $10^{13}$ & 1250 & 30 & 14 & $\mathrm{n}=5.3 \cdot 10^{12}$ & 80 \\
\hline 60 & $10^{14}$ & 1250 & 30 & 20 & $\mathrm{n} / \mathrm{p}=3 \cdot 10^{12}$ & 100 \\
\hline 60 & $10^{15}$ & 1250 & 30 & 157 & $\mathrm{n}=5.5 \cdot 10^{11}$ & 71 \\
\hline
\end{tabular}




\begin{tabular}{|c|c|c|c|c|c|c|}
\hline 120 & $10^{13}$ & 1250 & 30 & 9.5 & $\mathrm{n}=6.7 \cdot 10^{12}$ & 97 \\
\hline 120 & $10^{14}$ & 1250 & 30 & 16.3 & $\mathrm{n}=1.3 \cdot 10^{12}$ & 300 \\
\hline 60 & $10^{13}$ & 1300 & 10 & 20.6 & $\mathrm{n} / \mathrm{p}=8 \cdot 10^{12}$ & 38 \\
\hline 60 & $10^{14}$ & 1300 & 10 & 40 & $\mathrm{n} / \mathrm{p}=2.8 \cdot 10^{11}$ & 2.2 \\
\hline 120 & $10^{13}$ & 1300 & 10 & 63 & $\mathrm{n}=1.1 \cdot 10^{13}$ & 63 \\
\hline
\end{tabular}

\section{ACKNOWLEDGMENTS}

The work at NCSU was supported by the Office of Naval Research via contract N00014-96-1-0765 monitored by Mr. Max Yoder. R.F. Davis was supported in part by the Kobe Steel, Ltd. Professorship.

\section{REFERENCES}

1. O. Ambacher, J. Phys. D: Appl. Phys. 31, 2653 (1998).

2. S.W. King, J.P. Barnak, M.D. Bremser, K.M. Tracy, C. Ronning, R.F. Davis, R.J. Nemanich, J. Appl. Phys. 84, 5248 (1998).

3. C.B. Vartuli, S.J. Pearton, C.R. Abernathy, J.D. MacKenzie, E.S. Lambers, J.C. Zolper, J. Vac. Sci. \& Techn. B 14, 3523 (1996).

4. J.C. Zolper, J. Crystal Growth 178, 157 (1997).

5. J.H. Edgar (ed.), Group III Nitrides, London, INSPEC (1994).

6. J.C. Zolper, S.J. Pearton, J.S. Williams, H.H. Tan, R.J. Karlicek, R.A. Stall, Mater. Res. Soc. Proc. Vol. 449, 981 (1997).

7. H.H. Tan, J.S. Williams, J. Zou, D.J.H. Cockayne, S.J. Pearton, J.C. Zolper, R.A. Stall, Appl. Phys. Lett. 72, 1190 (1998).

8. S. Strite, P.W. Epperlein, A. Dommann, A. Rockett, R.F. Broom, Mater. Res. Soc. Proc. Vol. 395, 795 (1996).

9. S. Strite, A. Pelzmann, T. Suski, M. Leszczynski, J. Jun, A. Rockett, M. Kamp, K. J. Ebeling, MRS Inter. J. Nitride Res. 2, 15 (1997); J. Appl. Phys. 84, 949 (1998).

10. J.C. Zolper, J. Han, R.M. Biefeld, S.B. van Deusen, W.R. Wampler, S.J. Pearton, J.S. Williams, H.H. Tan, R.J. Karlicek, R.A. Stall, Mater. Res. Soc. Proc. Vol. 468, 401 (1998).

11. C. Ronning, K.J. Linthicum, E.P. Carlson, P.J. Hartlieb, D.B. Thomson, T. Gehrke, R.F. Davis, Mat. Res. Soc. Symp. Proc. Vol. 537 (1999) and MRS Internet J. Nitride Semicond. Res. 4S1, G3.17 (1999). http://nsr.mij.mrs.org/4S1/G3.17/

12. T.W. Weeks, Jr., M.D. Bremser, K.S. Ailey, E.P. Carlson, W.G. Perry, R.F. Davis, Appl. Phys. Lett. 67, 401 (1995); J. Mat. Res. 11, 1011(1996).

13. J.F. Ziegler, J.P. Biersack, and U. Littmark, The stopping and ranges of ions in solids, (Pergamon Press, New York, 1985).

14. S. A. Smith, C. A. Wolden, M. D. Bremser, A. D. Hanser, R. F. Davis, W. V. Lampert, Appl. Phys. Lett. 71, 3631 (1997).

15. see e.g.: E. Oh, H. Park, Y. Park, Appl. Phys. Lett. 72, 70 (1998) and ref. therein.

16. M. Dalmer, M. Restle, A. Stötzler, U. Vetter, H. Hofsäss, M.D. Bremser, C. Ronning, R.F. Davis, Mat. Res. Soc. Proc. Vol. 482, 1021 (1998).

17. E.P. Carlson, C. Ronning, R.F. Davis, unpublished. 
18. B.J. Pong, C.J. Pan, Y.C. Teng, G.C. Chi, W.H. Li, K.C. Lee, C.H. Lee, J. Appl. Phys. 83, 5992 (1998).

19. L. van der Pauw, Philips Res. Rep. 13, 1 (1958).

20. S.M. Sze, „Physics of semiconductor devices“, John Wiley \& Sons, New York (1988). 